\title{
Os particípios rizotônicos emergentes no Português Brasileiro e sua gênese histórica
}

\author{
The emerging rizotonic participles in \\ Brazilian Portuguese and its historical genesis
}

\author{
Luiz Henrique Milani Queriquelli* \\ Universidade Federal de Santa Catarina, Florianópolis, SC, Brasil
}

\begin{abstract}
Resumo: Este trabalho visa investigar a formação histórica de particípios rizotônicos emergentes no português brasileiro (como: "tinha falo, tinha compro, tinha chego, tinha perco, tinha trago, tinha escrevo, tinha faso", entre outros) a partir de duas perguntas investigativas básicas: de onde vem a avaliação social e/ou estilística positiva para formas rizotônicas (não apenas as emergentes, mas todas); e como surge essa variante emergente aparentemente espelhada na forma da primeira pessoa do indicativo presente. Com relação à primeira questão, o trabalho sugere que o início da valorização prestigiosa das formas rizotônicas está correlacionado aos processos de derivação erudita intensificados durante o período do "português clássico", por volta dos séculos XV e XVI. Quanto à segunda pergunta, os dados encontrados sugerem que essa variante surge ainda no romance, a partir de - entre outros processos - verbos de aspecto intensivo, que a partir do séc. IV tiveram o seu emprego restrito a construções passivas analíticas.
\end{abstract}

Palavras-chave: Linguística histórica. Particípios rizotônicos. Derivação erudita. Verbos de aspecto intensivo. Passiva analítica.

\begin{abstract}
This work aims to investigate the historical formation of emergent rhizotonic participles in Brazilian Portuguese (such as: "tinha falo, tinha compro, tinha chego, tinha perco, tinha trago, tinha escrevo, tinha faço," among others), from two basic questions: where does the positive social and/or stylistic evaluation for rhizotonic forms (not only the emergent ones, but all of them) come from; and how this emergent variant appears apparently mirrored in the form of the first person of the present indicative. Regarding the first question, the work suggests that the beginning of the prestigious valorization of the rhizotonic forms is correlated to the processes of erudite derivation intensified during the period of "classic Portuguese," around the fifteenth and sixteenth centuries. As for the second question, the data suggest that this variant appears in medieval Romance, from - among other processes - verbs with an intensive aspect, which from the fourth century onwards had their employment restricted to analytical passive constructions.
\end{abstract}

Keywords: Historical linguistics. Rhizotonic participles. Erudite derivation. Intensive verbs. Analytic passive.

\section{INTRODUÇão}

Em português, são tradicionalmente reconhecidos dois tipos de formas de particípio perfeito: a dita "regular", com sufixo em -do, acompanhado da vogal do tema

\footnotetext{
* Professor do Departamento de Língua e Literatura Vernáculas, Universidade Federal de Santa Catarina, Florianópolis, SC, Brasil; luizqueriquelli@yahoo.com.br
} 
em - $a$ ou em -i (e.g., cant(a) $\underline{d o}$, corr(i) $\underline{d o}$ ); e uma forma irregular, nem sempre predizível, sem sufixo, constituída de um radical verbal e a vogal do tema nominal, e que é denominada rizotônica - porque o acento natural recai sobre o radical - ou "forte" (e.g., preso, aceso, aceito, limpo, pago, ganho, gasto, pego, entregue etc.). Quando afirmo que a forma irregular ou rizotônica não tem sufixo (mas apenas as vogais temáticas nominais $o$ ou e), estou seguindo a interpretação de Mattoso Câmara (1975, p. 161), que também formulou uma importante observação sobre essa questão:

São convencionais os esforços da disciplina gramatical para limitar o número desses particípios perfeitos rizotônicos e definir rigorosamente o seu uso. Para a estrutura da língua o que essencialmente importa é a existência desses processos de formação, como mecanismo dinâmico que tende a se expandir.

Compartilhando a mesma posição de Mattoso Câmara, isto é, preocupada mais com a produtividade dos processos de formação dos particípios no PB do que com o disciplinamento e a prescrição de regras fixas, Miara (2013) estudou os chamados verbos abundantes (que oferecem particípios duplos), os seus padrões de formação participial e os fatores - linguísticos e sociais - que condicionam o uso de cada forma. A autora concluiu que, atualmente no $\mathrm{PB}$, o uso das formas regulares (as formas arrizotônicas, formadas com o prefixo - do) está diminuindo gradativamente, enquanto que o uso de formas rizotônicas está em tendência de crescimento, especialmente em textos escritos. Além disso, há avaliação social e/ou estilística positiva para formas rizotônicas, ao passo que, eventualmente, essa avaliação é negativa para a variante arrizotônica do mesmo verbo, o que também foi corroborado em Miara e Coelho (2016).

Ainda na década de 70, Mattoso Câmara (1975, p. 161) tinha afirmado ser “[...] digno de nota da morfologia portuguesa a tendência a incorporar na conjugação verbal novos particípios rizotônicos que ficam em variação livre com os particípios em -do de muitos outros verbos." A esse propósito, a descoberta mais interessante de Miara (2013) está justamente ligada à formação de formas rizotônicas: segundo a autora, há uma forte tendência em direção a um novo padrão na formação do particípio rizotônico; tal padrão é sua formação a partir do radical da $1 .^{a}$ pessoa do indicativo presente (1PIndP) (ex.: eu pago, eu ganho, eu gasto > part. pago, ganho, gasto em vez de pagado, ganhado, gastado). Portanto, hoje, é cada vez mais natural que tinha pago seja privilegiado em vez de tinha pagado, assim como acontece com tinha ganho ou tinha gasto. O mais surpreendente, no entanto, é que, conforme essa regra de produtividade constatada, particípios rizotônicos formados por outras raízes (geralmente raízes derivadas do supino latino, como veremos) tendem a ser substituídos pela variante aparentemente nova formada a partir de 1PIndP. Isso explica a ocorrência das seguintes formas emergentes, registradas no estudo de Souza (2011, p. 9):

1) Tinha falo:

"[...] eu tinha falo de uma sorveteria que era super famosa [...]"

"Como eu tinha falo a vocês [...]"

"[...] tinha falo com Rose e acabei confundindo tudo [...]"

2) Tinha compro:

"[...] tirei um pedaço do pão que tinha compro e dei pra ela [...]" 
"A diretora tinha compro os carimbos e não chegou até hoje [...]"

"[...] no caminho tinha compro um jogo [...]"

3) Tinha chego:

"Chegou julho, e o dinheiro já tinha chego aos 53 mil reais [...]"

"[...] o tempo de Lilthen já tinha chego ao fim [...]"

"[...] ela mal tinha chego em São Paulo não conhecia nada [...]"

“[...] quando tinha chego encontrou o padre mexendo no hábito de sua professora [...]"

"Eu já tinha chego a querer desistir desse blog [...]"

4) Tinha perco:

“[...] uma coisa que eu já tinha perco a* muito tempo [...]"

“[...] um ocidental que já tinha perco a moral da vida [...]"

5) Tinha trago:

"[...] eu tinha trago meu filhote [...]"

"[...] eu só tinha trago ração para ela [...]"

"[...] vi que nada tinha deixado e nada tinha trago comigo [...]"

"[...] a mãe dela tinha trago pra Almenara pensando que era dela [...]"

(2011):

E posso acrescentar, pelo menos, outros dois casos aos levantados por Souza

6) Tinha escrevo:

"Eu tinha escrevo mais coisas, mas eu fiz merda aqui e apagou tudo [...]"

"encontrou [...] um papel que ela tinha escrevo [...]"

7) Tinha faço:

"Tinha facso todos truque [...]"

"[...] tinha faço comida $[. .] "$.

Entre as muitas questões que poderiam ser formuladas a fim de compreender o problema em questão, interessam-me pelo menos duas: (1) De onde vem a avaliação social e/ou estilística positiva para formas rizotônicas? (2) Como surge essa variante aparentemente nova formada a partir de 1PIndP?

Com relação à primeira questão, como tentarei mostrar adiante, aparentemente, o início dessa valorização das formas rizotônicas está correlacionado aos processos de derivação erudita intensificados durante o período do "português clássico", por volta dos séculos XV e XVI. Quanto à segunda pergunta, ao que parece, essa variante surge ainda no romance, a partir de - entre outros processos - verbos de aspecto intensivo. Estas formulações serão mais bem detalhadas adiante e constituem, portanto, as principais hipóteses deste trabalho, as quais serão confrontadas com dados extraídos a partir de pesquisa filológica.

\footnotetext{
1 Ambos retirados do Corpus Brasileiro (GELC, PUC-SP).
} 


\title{
2 A GÊNESE DA AVALIAÇÃo POSITIVA SOBRE OS PARTICÍPIOS RIZOTÔNICOS
}

Quando terá começado essa avaliação social positiva para as formas rizotônicas? Se me é lícito lançar uma hipótese, suponho que o início dessa valorização das formas rizotônicas está correlacionado aos processos de derivação erudita intensificados durante o período do "português clássico", por volta dos séculos XV e XVI. Portanto, assim como a expansão das formas arrizotônicas - as chamadas formas regulares ou fracas, em -ado, $-u d 0^{2}$ e -ido - está diretamente ligada ao desenvolvimento e expansão dos vernáculos latinos, o resgate das ditas formas rizotônicas "clássicas" deve estar diretamente ligado ao momento em que o latim padrão era supervalorizado em detrimento do vernáculo, por razões obviamente políticas e ideológicas, ligadas à chegada do Renascimento na Ibéria e à afirmação daquela nova nação lusitana, cuja língua nacional deveria estar à altura das letras latinas clássicas. Como afirma Ilari (1997, p. 30):

\begin{abstract}
A outra tarefa dos renascentistas consistiu em enriquecer a língua através de uma convivência íntima com o latim clássico, redescoberto no período do humanismo. Nenhum grande escritor português desse período [clássico] tentou tornar-se famoso escrevendo diretamente em latim - um projeto de vida no qual havia embarcado um século antes uma de suas principais referências literárias, o italiano Francesco Petrarca. Mas os intelectuais portugueses do século XVI foram profundos conhecedores da língua latina. A necessidade de expressar a cultura de seu tempo obrigouos a criar uma série de termos novos, e esses termos novos acabaram sendo buscados, mais ou menos conscientemente, no latim e no grego clássicos.
\end{abstract}

Que fatos poderiam confirmar essa hipótese? Proponho que, primeiro, devamos verificar qual é a extensão da presença dos particípios rizotônicos no português arcaico e, em seguida, checar se houve alguma expansão no período posterior, o período clássico.

${ }^{2} \mathrm{O}$ particípio em - $u d o$, presente ainda hoje nas línguas românicas com exceção do português e do espanhol, existiu no português até o século XV, quando foi suplantado pela forma -ido basicamente por quatro motivos, conforme Harrys-Northall (1996): (1) embora a forma -udo também fosse nativa da Ibéria, a perda de prestígio do romance gálico (ao qual essa forma era associada) na Península Ibérica, devido ao enfraquecimento das relações com os franceses, contribui para o seu desaparecimento; (2) conforme provado por Malkiel (1992), a partir de certo momento, com o sucesso da forma -ido para particípios de 2. ${ }^{a}$ conjugação, -udo passou cada vez mais a se especializar como uma terminação para adjetivos (hoje temos adjetivos pejorativos em -udo ligados a partes do corpo); portanto, essa especialização funcional teria sido a causa do desaparecimento do -udo participial; (3) talvez o motivo mais importante foi a simplificação na morfologia verbal ibérica (redução de 4 conjugações para 3): as outras línguas que preservaram os particípios em -udo, também preservaram 4 conjugações; além disso, as estruturas vocálicas das conjugações em -er e -ir eram muito parecidas, apresentando mínimas diferenças: infinitivos (-er/-ir), indicativo pres. (-emos/-imos, -edes/-ides), imperativo plural (-ed/-id) e particípio $(-u d o /-i d o)$; fica claro que a forma -udo contrastava muito com as demais, e isso pode ter sido um fator influente para que o sistema "expulsasse" essa forma; além disso, muitos verbos antes terminados em -er passaram para a conjugação em -ir, e assim também o particípio passou para -ido (por ex., confunder e confundir); (4) por fim, houve grande produtividade na derivação de novos verbos com o infixo -esc- (ex., gradir/agrade(s)cer, falir/fale(s)cer, guarnir/guarne(s)cer, bastir/abaste(s)cer etc.), que tinha um significado incoativo; esses verbos, como mostram os exemplos, assumiram a conjugação em -er e semicategoricamente formavam o particípio em -ido; isso reforçou a associação entre a conjugação em -er e o particípio em -ido. 
Huber (1986[1933]), baseado em um corpus que inclui praticamente todos os textos arcaicos já descobertos, atesta no PA a predominante regularidade dos particípios fracos (arrizotônicos) em -ado, -udo e -ido, e afirma o seguinte em relação aos particípios rizotônicos:

O port. ant. conhece os seguintes particípios fortes (acentuados no radical): 1. em -s: preso < pe(n)su, despeso 'gasto' < dispe(n)su. - 2. em -t. cinto e junto \215, 1, dito $(1214)<$ dictu, beeito $\$ 214,1$, feito \ 81, treito (C.M. $78)<$ tractu, colheito < collectu e pelo modelo deste tolheito, uma vez que também o infinitivo tolher se transformou pelo modelo de colher $<$ colliggere; aberto, encoberto, encuberto (já adj.) < in-copertu, morto; quisto $<*$ quaestu em ves de quesitu (E. \ 195) com analogia da vogal do radical ao pret. perf. definido quis $(\mathbb{S} 402,4)$ visto (a par de veudo, viudo) < *vistu em vez de visu (E. \195). A este grupo pertencem também ido < itu e nado (a par de nacido) $<$ natu. Aposto < appos(i)tu é adjetivo ou advérbio (\$S 188, 2; 323).

Portanto, Huber (1986[1933]) não chega a registrar sequer duas dezenas de formas rizotônicas no PA.

Por outro lado, uma investigação empreendida com base nas obras dos príncipes de Avis (Livro da Montaria, Leal Conselheiro, Livro da Ensinança de Bem Cavalgar Toda a Sela, O Livro da Virtuosa Benfeitoria, Livro dos Ofícios) (Almeida, 1981) - um dos corpus mais representativos do português clássico renascentista - revelou a seguinte lista de particípios rizotônicos:

Quadro 1 - Derivação dos particípios rizotônicos no período clássico

\begin{abstract}
aberto (<apertum; aprire), absorto (<absol(u)tum ${ }^{3}$; absolvere), abstracto (<abstractum, abstrahere), aceito (<acceptus, accipere), acesa (<acce(n)sum; accendere), afecto (<affectum; afficere), aflito (<afflictus; affligere), grato (<gratum adj.), atento (<attentus, attendere), bento (<ben(edic)tum; ben(edi)cere), cativo (captivum; captivare), cego (<caecum adj.), cheio $\left(<*\right.$ che(n) $\mathrm{um}^{4}<$ plenum; implere $>$ encher), coberto (<coopertus; cooperire), concluso (<conclusum; concludere), confuso (<confusum; confundere), convicto (<convictum; convincere), correcto (<correctum; corrigere), corrupto (<corruptum; corrumpere), culto (<cultum; colere), defeso (<defe(n)sum; defendere), descalço (<1PIndP; descalçar <decalcare), directo (< $<$ directum; dirigere), disperso ( $<$ dispersum; dispergere), dissoluto ( $<$ dissolutum; dissolvere), distinto (< $<$ distinctum; distinguere), eleito (<electum; eligere), emerso (<emersum; emergere), envolto (<invol(u)tus; involvere), enxuto (<exsuctum; exsuccare), erecto (<erectum; erigere), escuro (<obscurum adj.), exausto (<exhaustum; exhaurire), expresso (<expressum; exprimere), expulso (<expulsum; expellere), extinto (<extintum; extingere), farto ( $<$ fartum; farcire), fixo (<fixum; figere), frito (<frictum; figere), ganho (<1PIndP; ganhar < gaagnar <* waiđanjan), gasto (<1PIndP; gastar < vastar < vastum adj.), imerso (<immersum; immergere), impresso (<impressum; imprimere), incluso (<inclusum; includere), incurso (<incursum; incurrere), infecto (infectum; inficere), inquieto (<inquietum; inquiescere), inserto (<insertum; inserire), isento (<exemptum; eximere), junto (< junctum; jungere), liberto (<libertum adj.), limpo (<limp(id)um adj.), manifesto ( $<$ manifestum; *manifendere), morto (<mortuus; morior), murcho (<murcho adj.), nado/nato (<natum; nascere), oculto (<occultum; occulere), omisso (<omissum; omittere), opresso (<opressum; oprimere), pago (<1PIndP; pagar $<$ pacare), perco (<1PIndP; perder < perdere), perverso (< perversum; pervertere), preso $(<$ pre $(\mathrm{n})$ sum; prendere), pretenso (<pretensum; pretendere), repulso (<repulsum; repellere), restrito (<restrictum; restringere), revolto ( $<\mathrm{revol}(\mathrm{u})$ tum; revolvere), roto (<ruptum; rumpere), salvo ( $<$ salvum adj.), seco (<siccum adj.), seguro (securum adj.), sepulto (<sepultum; sepelire), sito (<situm; sinere), solto (<sol(u)tum; solvere), submerso (<submersum; submergere), submisso (<submissum; submittere), sujo
\end{abstract}

${ }^{3}$ Síncope do $u$ átono e alternância das líquidas $r$ e $l$ (rotacismo).

${ }^{4} \mathrm{O}$ grupo - $p l$ - sofreu palatalização e se transformou em -ch- (primeiro com som de [t $\left.\int\right]$, depois, [J]). A raiz * plere aparecia sempre prefixada em verbos como complere, implere, replere, explere, opplere. 
(<suci(d)um adj.), sujeito (<subjectum; subicere), surto (sur(re)ctum; surgere), surpreso (<su(pe)rprehensum; superprehendere), suspeito (<suspectum; suspicere), suspenso (<suspensum; suspendere), tinto (<tinctum; tingere), torto (<tortum; torquēre), vago (<vagum adj.).

Fonte: Queriquelli (2016, p. 169).

Dos 85 particípios que constam nessa lista, 80 são derivados de suas formas latinas, sendo 78 por derivação erudita (ou a partir do particípio, ou a partir do adjetivo latino que derivara um verbo) e apenas dois por derivação popular (sujo e cheio), embora a analogia implere/plenum $>$ encher/cheio possa ser considerada uma derivação semierudita. Os outros 5 particípios da lista foram formados a partir de 1PIndP (descalç, ganho, gasto, pago e perco), o que mostra que esse processo já estava ativo por volta do século XV.

Além disso, dos 78 particípios formados por derivação erudita a partir de radicais latinos clássicos, 25 deles são eles mesmos os radicais de seus novos verbos portugueses, que apresentam isomorfia entre 1 PIndP e o particípio rizotônico. É o caso de: aceito (1PIndP e particípio de aceitar, e não de accipere), cego (1PIndP e particípio de cegar, sem verbo latino correspondente), disperso (1PIndP e particípio de dispersar, e não de dispergir < dispergere), expresso (1PIndP e particípio de expressar, e não de exprimir <exprimere), expulso (1PIndP e particípio de expressar, e não de expelir <expellere), farto (1PIndP e particípio de fartar-se, e não de farcire). O mesmo vale para fixo, frito, infecto, isento, junto, liberto, limpo, manifesto, oculto, salvo, seco, seguro, sepulto, solto, sujeito, surto e suspeito.

Desses resultados podemos inferir que há uma forte probabilidade de que os processos de derivação erudita intensificados no período do português clássico tenham dado início à tendência crescente de avaliação social positiva para os particípios rizotônicos em contextos formais, dado constatado ainda nos dias de hoje por Miara (2013) e Miara e Coelho (2016). Em outros termos, foi a partir do renascimento português (o dito período clássico da língua portuguesa) que seus falantes passaram a ver as formas rizotônicas (feito, aberto, por exemplo) como mais elegantes do que as arrizotônicas (fazido e abrido, por exemplo).

Se considerarmos que os textos do período clássico (do qual Os Lusíadas, a propósito, faz parte) foram a base para a tradição portuguesa de gramáticas prescritivas que até hoje elogiam o uso do particípio rizotônico, especialmente quando acompanhado dos auxiliares ser, estar e ficar, essa hipótese ganha ainda mais força. Afinal, isso gera um processo em cadeia: gramáticas prescritivas recomendam o uso da forma rizotônica; logo, os manuais de educação básica tradicionalmente endossam essa recomendação, inclusive ridicularizando o uso de certas formas arrizotônicas (como farido, abrido etc.).

Ciente disso, em contextos formais, o falante generaliza essa regra, agindo muitas vezes por hipercorreção: às vezes, mesmo quando a norma padrão prescreveria a forma arrizotônica, o falante usa a outra variante (e.g., ele tinha salvo o arquivo em vez de tinha salvado), julgando grosso modo que a forma "mais curta" é a mais certa; outras vezes, ele busca a forma "mais curta" no seu inventário, mas não a encontra, e então acessa os padrões morfológicos que a língua dispõe para "gerar" uma forma rizotônica. Ele se pergunta: existe um padrão ativo na lingua para derivar formas semelhantes a feito (fazer), revolto (revolver), aceso (acender) submerso (submergir)? Provavelmente ele concluirá que não há os sufixos derivacionais -to e -so disponíveis na língua de hoje para tal formação. Mas então nosso falante se perguntará inconscientemente: ora, para aceito 
(aceitar), atento (atentar), descalço (descalcar), disperso (dispersar), expulso (expulsar), fixo (fixar), junto (juntar), repulso (repulsar), salvo (salvar), solto (soltar), pago (pagar), existe sim um padrão bem perceptível: en aceito $>$ en tinha aceito; en expulso > eu tinha expulso; en salvo > eu tinha salvo etc. Em consequência, quando não há a forma clássica disponível no léxico do seu idioleto ou quando ela simplesmente não existe, - em vez de usar a forma regular, por medo de errar (já que "é feio falar abrido", mas ele simplesmente não adquiriu aberto) - ele acaba criando um novo particípio rizotônico espelhado na 1PIndP (por exemplo, "Tinha abro essa excę̧ão", como vimos nos dados autênticos acima). Eis o que será aprofundado na próxima seção.

\section{A GÊNESE DA NOVA VARIANTE RIZOTÔNICA ESPELHADA NA PRIMEIRA PESSOA}

Já temos, portanto, uma hipótese bastante plausível para explicar por que as formas rizotônicas são mais bem avaliadas socialmente hoje do que as arrizotônicas. No entanto, como surgem na língua essas variantes rizotônicas inovadoras espelhadas em 1PIndP? De que maneira o sistema passa a admitir essa possibilidade? Acredito que diferentes processos de derivação verbal ocorridos ainda nos períodos do romance ibérico e do português arcaico sejam a chave para essa questão. Particularmente, suspeito que os verbos de aspecto intensivo - como explicarei adiante - sejam largamente responsáveis por engendrar esse processo.

Os particípios têm um estatuto misto: fazem parte de paradigmas verbais, mas também são adjetivos. Assim sendo, têm uma vida semi-independente em relação aos verbos. Os verbos podem cair em desuso e, mesmo assim, os particípios correspondentes podem sobreviver, quer como particípios (eventivos) quer como adjetivos. Como observa Souza (2011), isso é muito menos comum com outras formas verbais, mas não é raro de ocorrer com particípios, que podem muito bem ser as únicas formas restantes de um paradigma verbal. Exemplos:

Quadro 2 - Formas participiais subsistentes no português

\begin{tabular}{|l|l|}
\hline († accipio, accipĕre, accēpi), acceptum. & Ptg. aceito, part. \\
\hline († quiesco, quiescĕre, quievi), quietum. & Ptg. quieto, adj. \\
\hline († promo, promĕre, prompsi), promptum. & Ptg. pronto, adj. \\
\hline († censĕo, censēere, censŭ $\imath)$, censum. & Ptg. censo, subst. \\
\hline († lugĕo, lugēere, luxi $),$ luctum. & Ptg. luto, subst. \\
\hline
\end{tabular}

Fonte: Souza (2011, p. 13).

Outros exemplos lembrados por Laurent (1999) são as formas certum (> certo), de cerno 'peneirar', e castum (> casto), de careo 'carecer, abster-se'.

No entanto, os particípios não derivam apenas particípios eventivos, adjetivos ou substantivos, mas podem também derivar novos verbos. Para compreender isso numa perspectiva da história linguística românica, é necessário ter em conta que os verbos latinos tinham, pelo menos, três radicais diferentes. Tomemos o exemplo do verbo laudo: 
Quadro 3 - Radicais dos verbos latinos (ex.: verbo laudo)

\begin{tabular}{|c|c|c|}
\hline Radical do presente (infectum): & laudā- & Tempos do aspecto infectum \\
\hline Radical do perfeito (perfectum): & laudā-v- & Tempos do aspecto perfectum \\
\hline \multirow[t]{3}{*}{ "Terceiro radical" (Aronoff, 1994): } & laudā-t- & Particípio perfeito: laudātus, a, um \\
\hline & & Particípio futuro ativo: laudātū rus, $a$, um \\
\hline & & Supino: laudātu $(m)$ \\
\hline
\end{tabular}

Fonte: Queriquelli (2016, p. 162).

$\mathrm{Na}$ deriva das línguas românicas, eventualmente os verbos se formaram a partir dos radicais do infectum ou do perfectum, mas muitos verbos derivaram do terceiro radical, convencionalmente chamado de radical do supino, dando origem a novos verbos. Segundo Aronoff (1994, p. 46), havia três tipos de verbos derivados com base no "terceiro radical" dos verbos latinos: desiderativos, iterativos (ou frequentativos) e intensivos. Os primeiros se formavam pelo acréscimo do sufixo -urio ao radical e exprimiam desejo, vontade. Assim se formaram os verbos românicos esurio 'estou com fome', de esum, particípio de edo 'comer'; parturio 'começar a dar à luz', de partum, particípio de pario 'conceber'. Os segundos se formavam com o sufixo -ito, pertenciam à $1 .^{a}$ conjugação e significam geralmente a repetição iterativa do que significava o verbo primitivo. Assim, dico 'dizer', pelo particípio dictum, derivou dictito 'tagarelar'. Os últimos eram formados simplesmente acrescentando terminações da 1. ${ }^{a}$ conjugação, com a vogal temática $-\bar{a}$ - à forma atemática do terceiro radical. Listo aqui alguns exemplos de verbos intensivos surgidos a partir de particípios:

- cantar, que surgiu de canto (cantum), antigo particípio de cano (cano, canere, cecini, cantus).

- expulsar, que surgiu de expulso (expulsum), antigo particípio de expelir (expello, expellere, expuli, expulsus).

- juntar, que surgiu de junto (juntum), antigo particípio de jungir (jungo, jungere, junxi, junctus).

- findar, que surgiu de findo (finitum), antigo particípio de finio (finio, finire, finivi, finitus).

- fixar, que surgiu de fixo (fixum), antigo particípio de figo (figo, figere, fixi, fixus).

- aceitar, que surgiu de aceito (acceptum), antigo particípio de accipio (accipio, accipere, accepi, acceptus).

O particípio que originou esse novo verbo, também passou a ser particípio dele, embora também surgisse uma nova forma arrizotônica (e.g., aceito $>$ aceitar $>$ part. aceito e aceitado). Entretanto, a isomorfia entre o particípio rizotônico (e.g., aceito) e a 1PIndP (eu aceito) passa a ser sistematizada pelos falantes, dando origem a um processo de sincretismo direcional.

\subsection{Sincretismo direcional}

Conforme Souza (2011, p. 6), uma propriedade frequente dos sistemas flexionais é o fato de que "[...] duas ou mais células do paradigma de um lexema podem ter uma coincidência em forma, embora sua função não coincida. Esse é o chamado 
sincretismo [...]." Um exemplo desse tipo de situação é a encontrada nos casos de etimologia popular em que:

[...] uma semelhança no significante é ancorada numa palavra fazendo com que haja uma alteração leve no significante de acordo com o que é sentido pelos falantes como algo relacionado. Por exemplo, a expressão casa geminada, em que geminado está relacionado etimologicamente à palavra gêmeo. Como para boa parte dos falantes essa ligação é opaca, alguns acabam alterando a forma do adjetivo para germinada, que embora não faça sentido semanticamente, já que as casas não germinam, pelo menos fornece uma associação com um significante existente. (Souza, 2011, p. 6)

Esse conceito é visto com certa crítica pela morfologia distribuída, encabeçada por Halle e Marantz (1993), segundo os quais nenhuma situação de sincretismo é arbitrária, sendo sempre baseada na existência de traços morfossintáticos comuns ou de defaults. Conforme essa análise, então, os particípios rizotônicos emergentes seriam formas default baseadas em 1PIndP mais morfemas de gênero e número - ou, conforme a análise de Mattoso Câmara (1975) que mencionei na abertura desta seção, baseadas no radical do infinitivo e eventuais alomorfias mais vogal temática nominal (e só depois em morfemas de gênero e número). No entanto, segundo Souza (2011), esse tipo de análise teria problemas para explicar certas evidências de sincretismo: por exemplo, o fato de que esse particípio rizotônico emergente não concorda em gênero e número, e só é possível na voz ativa 5 .

Portanto, caso se trate realmente de um sincretismo e ele seja direcional, "podemos formalizar o que ocorre através de uma regra de remissão em operação nesses casos" (Souza, 2011, p. 6). Logo, é preciso identificar a qual célula do paradigma o particípio remete. Essa forma à qual o particípio tende a se assimilar pode ser considerada seu atrator, que determina a direção do sincretismo.

Uma vez que esse particípio não concorda em gênero e número, e só aparece na voz ativa, ou seja, uma vez que ainda não são possíveis as flexões fala* falos* e falas* ou escreva*, escrevos* e escrevas*, o único atrator possível é a forma de 1PIndP. A probabilidade de que a forma de 1 PIndP seja o atrator para esse sincretismo direcional pode ser endossada pelo conceito de ilha de confiabilidade, proposto por Albright (2002, p. 686):

\begin{abstract}
One method of hypothesizing rules for a morphological change is the minimal generalization algorithm, sketched by Pinker and Prince (1988:13034) and developed further by Albright and Hayes (2002). The premise of this approach is that language learners explore the space of possible phonological environments, looking for those that have especially high reliability for a given change. An environment is said to be an island of reliability when its reliability value is higher than the general reliability of a change.
\end{abstract}

Assim, considerando que os falantes nativos encontraram uma ilha de confiabilidade na forma de 1 PIndP, estaríamos diante de um caso de sincretismo direcional, "em que o particípio espelha a primeira pessoa do singular do presente do

5 Usando os exemplos vernáculos que expus antes, podemos encontrar "eu tinha falo de uma sorveteria que era super famosa", mas por enquanto ainda não encontramos "a sorveteria que foi fala* por mim é famosa"; encontramos "Eu tinha escrevo mais coisas", mas ainda não encontramos "mais coisas foram escrevas* por mim". 
indicativo do verbo" (Souza, 2011, p. 8). Trata-se de um caso mencionado em Baerman (2005, p. 823), uma situação que é "clearly systematic and that involves morphosyntactic values so remote from each other that any account in terms of natural classes would void the notion of any explanatory value." Por isso, uma análise baseada em subespecificação e defaults seria inviável.

\subsection{Como essa nova variante se torna produtiva no PB}

Agora, ciente da agência do sincretismo direcional na formação do particípio rizotônico em análise, podemos traçar o seguinte cline:

1. Os particípios têm uma vida paralela aos verbos; muitas vezes os verbos podem desaparecer, e seus particípios, sobreviver, dando origem a novos verbos. Isso aconteceu na história românica, principalmente com verbos intensivos ${ }^{6}$.

2. O particípio que originou esse novo verbo, também passou a ser particípio dele, embora também surgisse uma nova forma arrizotônica (e.g., aceito $>$ aceitar > part. aceito e aceitado).

3. Entretanto, a isomorfia entre o particípio rizotônico (e.g., aceito) e a $1 .^{a}$ sing. do ind. presente (eu aceito) passa a ser sistematizada pelos falantes, dando origem a um processo de sincretismo direcional.

4. Outros verbos que não apresentavam isomorfia entre o particípio rizotônico e a 1PIndP, por esse processo, passam a derivar particípios espelhados nesta última forma (e.g., ganho, pego, gasto, pago 7 ).

5. Verbos abundantes cujo particípio rizotônico era derivado do antigo particípio latino (radical do supino), como fazerer, passam a ter até três particípios: fazido, feito e faço. O mesmo para escrever. escrevido, escrito e escrevo.

\subsection{Os verbos intensivos e sua especialização em construções passivas}

Mas por que os demais radicais desses verbos desaparecem e só sobrevive o radical do particípio? Aparentemente, a resposta está no fato de que esse tipo de verbo (intensivo) passou a ser usado, no romance, predominantemente em construções passivas, que nessa época já eram mormente analíticas (verbo ser + particípio).

Conforme debati em Queriquelli (2016), a partir de Posner (1996), Pinkster (2015), Nunes (1991), Neves (2014) e Ferrari Neto et al. (2010), no século IV d.C., a passiva românica tinha se tornado perifrástica, como se pode compreender no esquema a seguir:

\footnotetext{
${ }^{6}$ Vimos os seguintes exemplos antes: cantar, que surgiu de canto (cantum), antigo particípio de cano; expulsar, que surgiu de expulso (expulsum), antigo particípio de expelir (expellere); juntar, que surgiu de junto (juntum), antigo particípio jungere; findar, que surgiu de findo (finitum), antigo particípio de finire; fixar, que surgiu de fixo (fixum), antigo particípio de figere; aceitar, que surgiu de aceito (acceptum), antigo particípio de accipere.

7 Pode ser que pago tenha surgido a partir do substantivo deverbal paga (arcaico). Contudo, mesmo que essa tenha sido a origem, o fato é que essa forma também conflui para o processo de sincretismo direcional ligado à forma da 1 PIndP.
} 
Quadro 4 - Passiva no paradigma clássico e no paradigma românico

\begin{tabular}{|l|l|}
\hline \multicolumn{1}{|c|}{ Paradigma clássico } & \multicolumn{1}{c|}{ Paradigma românico } \\
\hline $\begin{array}{l}\text { expellor }=\text { sou expulso } \\
\text { expulsus sum }=\text { fui expulso }\end{array}$ & $\begin{array}{l}\text { expellor }(\dagger) \\
\text { expulsus sum }=\text { sou expulso } \\
\text { expulsus fuit = fui expulso }\end{array}$ \\
\hline
\end{tabular}

Fonte: Queriquelli (2016, p. 162).

Assim, a partir desse período em diante, particularmente no caso de verbos de aspecto intensivo, que por questões semânticas ligadas aos seus papeis temáticos se especializaram em construções passivas ${ }^{8}$, encontrávamos os verbos intensivos apenas em construções como:

8) Aristides expulsus est patria quod justus fuit (Cyriacus Morelli, Rudimenta, p. 374)

Aristides foi expulso da pátria porque foi justo

Mas raramente (talvez nunca) em construções como:

9) Aliqui Aristidem patria expulit (†) ...

Alguém expulsou Aristides da pátria ...

O mesmo se pode dizer dos seguintes exemplos:

10)Matrimonio junctus est Nis (Lexicon Syriacum, p. 314)

Nise foi juntado/se juntou em matrimônio

11)Pater matrimonio Nisem junxit $(\dagger)$

O padre uniu/jungiu Nise em matrimônio

12)Ille pro vobis fixus est in cruce (Commentaria in Vetus et Novum Testamentum, XXII)

Ele foi fixado na cruz por vocês

13) Aliqui pro vobis illum figit in cruce $(\dagger)$

Alguém o fixa na cruz por vocês

Quando novos verbos como expulsar, juntar e fixar surgem, seu particípio consequentemente já nasce também espelhado na 1PIndP:

- eu expulso/ eu tinha expulso

- eu junto/eu tinha junto

- en fixo/en tinha fixo

Esse processo, ao lado de outros, faz surgir a regra de produtividade de novos particípios rizotônicos espelhados na 1 PIndP, que já na época do português clássico se observa espraiada para outros verbos e hoje em dia se encontra em franca ascensão. Essa é uma hipótese que encontra eco em Sousa (2011) e Albright (2002), no entanto

${ }^{8}$ Por razões semelhantes, o latim desenvolveu verbos depoentes a partir de verbos indoeuropeus que só se comportavam na voz média (reflexiva), que compartilhava o mesmo paradigma da passiva (cf. Baldi, 1975). 
ainda carece de um maior volume de dados empíricos que a sustentem com alguma segurança.

\section{CONSIDERAÇÕES FINAIS}

No início deste artigo, levantei basicamente duas questões: de onde vem a avaliação social e/ou estilística positiva para formas participiais rizotônicas; e como surge a emergente variante participial rizotônica no PB, aparentemente nova, formada a partir de 1 PIndP.

Com relação à primeira questão, vimos que o início dessa valorização das formas rizotônicas deve estar correlacionado aos processos de derivação erudita intensificados durante o período do "português clássico", por volta dos séculos XV e XVI, quando os radicais latinos clássicos (entre eles, os particípios rizotônicos) foram exaustivamente injetados na língua, com evidente conotação prestigiosa. Quanto à segunda pergunta, ao que parece, essa variante surge ainda no romance, a partir de entre outros processos - verbos de aspecto intensivo, que - acreditamos - eram usados exclusivamente em construções passivas, fazendo com que somente o radical participal permanecesse na língua, derivando assim novos verbos a partir dele, sendo que tais novos verbos nasciam com o particípio rizotônico idêntico à forma de 1PIndP.

A resposta que encaminhamos para a primeira pergunta dispõe de um embasamento empírico mais robusto, ao passo que a resposta esboçada para a segunda pergunta ainda carece de dados factuais mais consistentes, embora encontre respaldo em outros estudos.

\section{REFERÊNCIAS}

Albright A. Islands of reliability for regular morphology: evidence from Italian. Language. 2002;78(4):684-709.

Almeida L, editor. Obras dos Príncipes de Avis: Livro da Montaria, Leal Conselheiro, Livro da Ensinança de Bem Cavalgar Toda Sela, O Livro da Virtuosa Benfeitoria, Livro dos Ofícios. Introd. e revisão de Lopes de Almeida. Porto: Lello \& Irmão Editores; 1981.

Aronoff M. Morphology by itself: stems and inflectional classes. Cambridge, Massachusetts: Massachusetts Institute of Technology Press; 1994.

Baerman M, Brown D, Corbett GG. The syntax-morphology interface: a study of syncretism. Cambridge: Cambridge University Press; 2005.

Baldi P. Remarks on the latin R-form verbs. Zeitschrift fur vergleichende Sprachforschung. 1975;90(1):222-57.

Ferrari Neto J, Silva CRT, Fortes F. A interpretação passiva/indeterminada de construções com a partícula se. DLCV, 2010,jan./jun.;7(1):39-56.

Halle M, Marantz A. Distributed morphology and the pieces of inflection. In: Hale K, Keyser SJ, editores. The view from building 20: essays in linguistics in honor of Sylvain Bromberger. Cambridge, MA: MIT Press; 1993. 
Harris-Northall R. The Old Spanish participle in -udo: its origin, use, and loss. Hispanic Review, 1996, winter;64(1):31-56.

Huber J. Gramática do português antigo. Trad. de Maria Manuela Gouveia Delille. Lisboa: Fundação Calouste Gulbenkian; 1986[1933].

Ilari R. Linguística Românica. 2a ed. São Paulo: Ática; 1997.

Laurent R. Past participles from Latin to Romance. Oakland: University of California Press; 1999.

Mattoso Câmara Júnior JM. História e estrutura da língua portuguesa. Rio de Janeiro: Padrão; 1975.

Miara FLJ. Particípios duplos: usos, desusos e alguns “intrusos”. Florianópolis: Universidade Federal de Santa Catarina; 2013.

Miara FLJ, Coelho IL. Particípios duplos: norma, avaliação e uso escrito. Cadernos de Letras da UFF. 2016,jan.;25(51). [citado 09 mai. 2018]. Disponível em:

http://www.cadernosdeletras.uff.br/index.php/cadernosdeletras/article/view/224.

Neves G. A voz passiva no latim vulgar. Ciberdúvidas da língua portuguesa, 10 dez. 2014. [citado 26 mar. 2015]. Disponível em: http://www.ciberduvidas.com/pergunta.php?id=32908.

Nunes J. Se apassivador e se indeterminador: o percurso diacrônico no português brasileiro. Cadernos de Estudos Linguísticos. 1991,jan./jun.;20(1):33-58.

Pinkster H. Oxford Latin syntax, volume 1: the simple clause. Oxford: OUP Oxford; 2015.

Posner R. The romance languages. Cambridge: Cambridge University Press; 1996.

Queriquelli LH. Permanências e reincidências latinas do português brasileiro: uma proposta de ensino de latim via linguística histórica. Florianópolis: Universidade Federal de Santa Catarina; 2016.

Souza PC. Particípios atemáticos no PB: um processo paradigmático. ReVEL. 2011; esp.ed.(5):1-30. [citado 25 ago. 2015]. Disponível em:

http://www.revel.inf.br/files/artigos/revel_esp_5_participios_atematicos_no_pb.pdf. 